\section{Increased Adiponectin Levels in Women with Rheumatoid Arthritis After Etanercept Treatment}

\section{To the Editor:}

We read with great interest the report by Dr. Nagashima, et al, "Increase in plasma levels of adiponectin after administration of anti-tumor necrosis factor (TNF) agents in patients with rheumatoid arthritis"1. The article is of special importance in regard to accelerated atherosclerosis among patients with connective tissue disease, including rheumatoid arthritis (RA). In the study, the elevation of total and high molecular weight adiponectin was observed in patients with RA treated with both etanercept and infliximab.

To support the observations of those authors, we share our experience with etanercept-related adiponectin changes in a group of 18 women with RA. We determined the plasma adiponectin levels before and after 3 months of treatment with etanercept and compared the results with healthy age-matched women. In patients with RA, the serum adiponectin concentration was measured before treatment and after 3 months. We also measured the total fat mass (TFM) by dual energy x-ray absorptiometry before treatment in patients and compared to controls. The levels of adiponectin were significantly higher in patients before treatment than in healthy controls, and was not related to TFM (there were no significant differences in TFM between the patient and control groups). We observed significant elevation of adiponectin levels after 3 months' treatment with etanercept; that is in agreement with the results of Nagashima, et al. We found that increment of adiponectin level was not related to change in disease activity (Disease Activity Score 28-joint count). This suggests that changes in adiponectin level may be caused by the direct influence of proinflammatory cytokine cascades on adiponectin concentration, rather than the general inflammation state ${ }^{2}$

The role of adiponectin in driving the inflammation in RA is still controversial. Some studies showed a proinflammatory effect of adiponectin with the secretion of interleukin 6 (IL-6) and matrix metalloproteinase-1 from synovial fibroblasts in patients with $\mathrm{RA}^{3,4}$. However, others suggest antiinflammatory properties of this adipocytokine instead ${ }^{5-7}$.

We are inclined to recognize an antiinflammatory role for adiponectin, and suggest that TNF- $\alpha$ is a key cytokine that regulates adiponectin level in patients with RA. Huang, et $a l^{8}$ showed that initial TNF- $\alpha$ release from macrophages mediated by the globular form of adiponectin was inhibited by subsequent induction of antiinflammatory IL-10 synthesis. In the study by Yamaguchi, et $a l^{9}$, the globular form of adiponectin inhibits differentiation of osteoclasts, which may explain the halting of bone resorption observed among patients receiving anti-TNF- $\alpha$ treatment. It is not entirely clear whether all anti-TNF- $\alpha$ agents used in RA have the same effect on adiponectin level. It seems that contradictory results reported in the literature reflect different levels of TNF- $\alpha$ suppression and subsequent adiponectin changes whose level is higher when TNF- $\alpha$ reduction is not prominent.

MACIEJ LEWICKI, MD; PRZEMYSLAW KOTYLA, MD, PhD; EUGENIUSZ KUCHARZ, MD, PhD, FACP, Department of Internal Medicine and Rheumatology, Medical University of Silesia, Ziolowa 45/47, Katowice, 40-635, Poland. Address reprint requests to Dr. Kotyla. E-mail: pkotyla@slam.katowice.pl

\section{REFERENCES}

1. Nagashima T, Okubo-Fornbacher H, Aoki Y, et al. Increase in plasma levels of adiponectin after administration of anti-tumor necrosis factor agents in patients with rheumatoid arthritis. J Rheumatol 2008;35:936-8.

2. Lewicki M, Kotyla P, Kucharz E. Etanercept increases adiponectin level in woman with rheumatoid arthritis. Clin Rheumatol 2008:27:1337-8.

3. Ehling A, Schäffler A, Herfarth $\mathrm{H}$, et al. The potential of adiponectin in driving arthritis. J Immunol 2006;176:4468-78.

4. Tang CH, Chiu YC, Tan TW Yang RS, Fu WM. Adiponectin enhances IL-6 production in human synovial fibroblast via AdipoR1 receptor, AMPK, p38 and NF B pathway. J Immunol 2007;179:5483-92.

5. Senolt L, Pavelka K, Housa D, Haluzík M. Increased adiponectin is negatively linked to the local inflammatory process in patients with rheumatoid arthritis. Cytokine 2006;35:247-52.

6. Takemura Y, Ouchi N, Shibata R, et al. Adiponectin modulates inflammatory reactions via calreticulin receptor-dependent clearance of early apoptotic bodies. J Clin Invest 2007;117:375-86

7. Lee SW, Kim JH, Park MC, Park YB, Lee SK. Adiponectin mitigates the severity of arthritis in mice with collagen-induced arthritis. Scand J Rheumatol 2008;37:260-8.

8. Huang H, Park PH, McMullen MR, Nagy LE. Mechanisms for the anti-inflammatory effects of adiponectin in macrophages. J Gastroenterol Hepatol 2008;23 Suppl:S50-3.

9. Yamaguchi N, Kukita T, Li YJ, et al. Adiponectin inhibits induction of TNF-alpha/RANKL-stimulated NFATc1 via the AMPK signaling. FEBS Lett 2008;582:451-6.

J Rheumatol 2009;36:6; doi.10.3899/jrheum.081192 